\title{
Audiovisual Constructs of Paralympic Games: Scalarity and Camera Angle
}

\author{
Sebastián Sánchez Castillo ${ }^{*}$, María Teresa Mercado Sáez ${ }^{2}$ \\ ${ }^{1}$ Department of Theory Languages and Communication Sciences, University of Valencia, Valencia, Spain \\ ${ }^{2}$ Department of Journalism and Communication, Universidad CEU Cardenal Herrera, Valencia, Spain \\ Email: "sebastian.sanchez@uv.es
}

Received 3 February 2014; revised 10 March 2014; accepted 20 March 2014

Copyright (C) 2014 by authors and Scientific Research Publishing Inc.

This work is licensed under the Creative Commons Attribution International License (CC BY).

http://creativecommons.org/licenses/by/4.0/

(c) (i)

Open Access

\begin{abstract}
This research will analyze the variables differentiating between the audiovisual television of the XIII edition of the Paralympic Games and the Games of the XXIX Olympiad, held in Beijing from the 7th of September to the 17th, 2008. This study will serve as a methodological basis for similar future research. By means of a qualitative and quantitative methodology, this study also focuses on determining if TV representations of Paralympic sportspersons favour their social integration or if, on the contrary, lead to higher stigmatization.
\end{abstract}

\section{Keywords}

Paralympic Games Broadcast; Sport Society; Contents Analysis; Media Representation and Disability; TV Narrative

\section{Introduction}

The Paralympic Games can be considered one of the few possibilities available to the handicapped for attracting media attention, forming a message with their demands and claim for participation in social partiality. Although the Olympic and Paralympic games are officially considered as parallel events, the Paralympic Games are often referred to as the poor cousin of the Olympic Games and are given fewer funds by the government and other public institutions (Kell et al., 2008; Goggin \& Newell, 2005).

Television sports broadcasts can trigger emotions, sensations and feelings in the audience. Blanco (2001) defines them as a "spectacular genre of journalism which, in its efforts to inform at the same time as a sports event is actually happening, exploits the medium's communication possibilities-determined by the combination of narrative techniques used by the professionals involved (journalists, camera operators, producers, sound operators, etc.) and by the spectacular use of available technologies-with the intention of generating a drama able to "Corresponding author. 
keep the spectator's interest”.

The technical arrangements able to generate this information are defined in a style book previously drawn up by the International Olympic Committee and the television company handling the broadcasting. This sets fixed parameters - a particular size and length of the shots in foreseeable situations, such as for example when runners reach the finishing line-and the strategic layout of all the technical and technological paraphernalia. This is why there needs to be an analysis of the criteria forming the basis for the fundamental audiovisual narration defining the coverage that the television medium gives of Paralympic sportspersons.

The media has an essential responsibility in the production and reproduction of these social portrayals, as well as the "reinforcement of norms and attitudes present in our societies” (Léséleuc, Athanasios, \& Marcellini, 2009: p. 82). Sometimes the representation of a disability in the media attempts to soothe a predominantly healthy audience as to the stability of their identity as non-handicapped (Longmore, 1987).

In the sports field, it needs to be worked out which values are most compelling and which are devalued in sports competitions of people with disability, as this would help to understand how the process of transforming the social image of disability is formed starting from the sports context, a domain in which destigmatisation is effectively accomplished, and inversely, to what extent sport produces or reproduces a stigmatisation (Schantz, 2001; Marcellini \& Léséleuc, 2003).

A lower presence of handicaps such as intellectual or mental disabilities and cerebral paralysis can also be quantified and there are cases of certain shortcomings being covered up. As for the visibility of prosthetic devices, the wheelchair comes forward as a stock feature of disability, with other prosthetic items being concealed. Sometimes the media portray Paralympic sportspersons as "supermen in wheel chairs” (Goggin, 2008: pp. 8788).

Scientific knowledge in social psychology and disability psychology (Bogdan \& Taylor, 1989; Oliver \& Barnes, 1998) has helped to confirm that people with handicaps are "the subject of globally negative social representations in European societies, being considered less valid (credible?), and are consequently prone to a form of stigmatisation in society” (Goffman, 1963; Léséleuc, Athanasios, \& Marcellini, 2009: p. 81).

There is widespread agreement that "media attention has changed the Paralympic Games into a major sports event” (Howe, 2008: p. 135). It has nevertheless also been proven that the media do not have a similar perception of disability sports and sportspersons with no disability, in spite of the possible initial idea that participation in top-level competition might enable the social image of the disabled to be positively transformed by drawing this closer to the image of sportspersons (Schantz, 2001; Marcellini \& Léséleuc, 2003).

If the existence of this objective differentiation is accepted, the basic question would be to find out whether this contributes to the process of stigmatisation or destigmatisation of these persons, in their social normalisation.

\subsection{The Media Stereotype of Athletes with Disability}

From the audiovisual communication viewpoint, when a sports event is broadcast a spatial reference framework for the spectator is selected by the producer, who is in charge of the narrative process: this involves the lighting, the camera angle, the perspective stemming from the scalar quality of the shots, their balance and length, ending up in a designed composition, i.e., the form in which the information is presented (Taylor, 1964; Sontag, 1977; Monaco, 1977).

The choice of the angle, perspective and the compositional scale may affect the spectator's understanding and the later memory of the audiovisual message (Kraft, Patterson, \& Mitchell, 1986; Arnheim, 1974), developing a real audiovisual metaphor. These metaphors may be created in the post-production (Mitry, 1978) or in the internal editing of the staging narrative by means of deliberately caused scalar properties or angulations. Hence, there are visual expressions of primary metaphors in audiovisual discourse.

In an experimentally-based piece of research Mandell and Shaw (1973) verified the effect of the angles of camera shots in the perception of an interviewed person, thus indicating the importance of considering and studying compositional forms to understand how these are construed and perceived by the audiences of these discourses.

Other studies performed on the journalistic photographic treatment of the disabled show that the way this group is visually portrayed talks of how they are seen by society. According to Beth Haller's experimental works, the camera angle has been used as a dependent variable to find out the cognitive implications of this type of visual composition and their adaptation to Clogston's models of representation of disability (Haller, 1995: p. 3). 
Although the position in which the camera is placed in respect of handicapped persons may lack importance in the final making of the audiovisual product, this spatial choice has great cognitive implications in terms of representation, since, "without even saying a word, a particular camera angle can represent a person with a disability as someone passive and dependent, as an equal, or as a superhero" (Haller, 1995: p. 4).

Kraft (1987) used a multivariate analysis of covariance for three consecutive scenes shown in order to relate the observer's state of mind to pictures of people taken from different angles. The main conclusion of this experiment was that the camera angle can deeply affect the memory and the portrayal that spectators attribute to pictorial events. Another empirically-based study showed that there may be a slight correlation between the photographer's credibility and the camera angle used (Tiemans, 1970). Ellis (2008), Norden (1994) and Maathuis (2010), furthermore point out that the camera angle has the power to stress disability and provide important data for understanding how people with disability are presented as inferiors by the visual media, thus undergoing certain processes of social stigmatisation.

From the idea that people with disability may achieve sports or social accomplishments which may prove incredible for non-dependent people, the low visual angle may give a dependent person a superiority status, subtly exalting their disability. On the other hand, shots from above give a pious, weak image, creating an inferior status with the paternalistic stereotype found in many pictures of people with disability (Haller, 1995: p. 6).

\subsection{The Media Stereotype of Athletes with Disability}

The term "stigma" is used when a physical feature of an individual or group arouses a negative response from persons not having that characteristic (Pappous et al., 2009: p. 34). It may also be considered as being a deviation of established norms, according to Goffman (1963) and Susman's theory (1994).

The impartial reality of disability is questioned, by considering that deviation is not an inherent condition, but a negative label that some people apply to others which causes marginalisation (Goffman, 1963; Pappous et al., 2009). People with disability represent a significant social minority "but continue to be ignored, stereotyped and stigmatised” (Hardin, 1999: p. 1). For many people with some degree of dependence, this means a lesser handicap than stereotyped attitudes and barriers (Scotch, 1988: p. 164).

The media very often present disability as a "marker of vulnerability" (Sutherland, 1997: p. 18), in the same way as they describe the disabled as a fragile group in society, not through their physical limitations, but "due to the possibility of undergoing social exclusion” (Beckett, 2006: p. 3). Experts in communication and disability such as Green and Tanner (2009) defend the standpoint that the media may perpetuate the subjective and negative image of people with disability, contributing to stigmatisation and consequently to the discriminatory attitudes towards the disabled in society. These media may also help to perpetuate stereotyped portrayals of disability, conveying sensations of pity, weakness and dependence (Cooke, Daone, \& Morris, 2000), or may on the other hand "promote more positive images, thus contributing to the inclusion process for the disabled" (Pappous et al., 2009: p. 33).

These media have a decisive role, as they reflect and reinforce social disability and show people with disability as an underprivileged, weak group. The representation of disability and what it means to be disabled is normally created through stereotypes (Norden, 1994; Barnes, 1992). Ultimately, media coverage of disabled athletes is attempting to construct the limits of social normality (Ellis, 2009), but in the framework of the social model of disability, Barnes (1992: p. 19) seems concerned, as "stereotypes are a distortion of the reality of disability”.

In her research DePauw (1995) assert that practising sport can be a highly important matter for promoting independence, self-esteem and social and working integration of the disabled, but also that "their efforts and athletic qualities are seen with greater admiration than non-dependent sportspersons" (Schell \& Duncan, 1999: p. 33), in audiences that try to reassure themselves that "if a disabled person makes enough effort, they may even appear normal” (Barnes, 1992: p. 13).

Since the media presence of the body may mean a social construct (Hartmann-Tews \& Rulofs, 2001), it is unquestionable that the massive exposure of these sportspersons may benefit the process of destigmatising people with physical, psychic or sensorial limitations. Hence, different people in the social construction of the image of the disabled body "take a place and play an extremely important role in the process of social inclusion of people with disabilities, both in their stigmatisation and in their destigmatisation” (Pappous, et al., 2009: p. 4).

From this standpoint, one might think that "the media play an extremely important role in the process of stigmatising and destigmatising the disabled, depending on the place that these are assigned and the texts and illu- 
strations that they produce in this respect, the aspects that they choose to cover or the ones they miss out" (Léséleuc, Athanasios, \& Marcellini, 2009: p. 84).

While photographs of Paralympic athletes are often framed in such a way as to conceal the disability so that the person looks more able at sport (Ellis, 2009: p. 30), the first step in rendering proper portrayals of disability is to include images with mutilations and physical deterioration that are difficult to accept (Thomas \& Smith 2003).

To learn to what extent the media are involved in the process of stigmatisation or destigmatisation of the disabled through media coverage of the sports events intended for these people, one needs to answer the question "how are disability and people with these limitations represented by the media?" and also "is there any differentiation between this discourse and the one used by the media for people without disabilities?"

Previous studies made of this subject can lead to a conclusion as to what visual treatment has been given to Paralympic sportspersons by the media. It is also necessary to find out how and to what extent these possible differentiations are structured in the portrayal. These two considerations will elucidate the media coverage of Paralympic games, and help to bring to light any possible forms of social stigmatisation undergone by athletes with disability, because disability is a social, cultural and political category (Goggin, 2008), and they have "to negotiate their physical differences along with the social stigma that they suffer” (Mitchell \& Snyder, 2000: p. 3). That was the ultimate intention of this research.

\section{Study Hypothesis}

This piece of research analyses the differentiating variables between the audiovisual television production of the 13th edition of the Paralympic Games and the Games of the 29th Olympiad, held in Peking from 7th to 17th September 2008.

The starting hypotheses are established from the experimental research mentioned above, in which the angular position of the subject facing the camera and its relationship with any possible resulting cognitive implications were analysed. This particularly took into account Haller's (1995), Ellis' (2008) and Knoll's (1987) conclusions, which established the bases for correlating the visual representation of dependent persons in the media and the social normalisation of disability, and how it was possible to construct disability as a social concept from these.

The resolution of the hypotheses will help to construe if the comparative visual coverage of the Olympic and Paralympic Games, as a television narrative model, may help to perpetuate the stereotyped representations of disability, as indicated in the research done by Cooke, Daone and Morris (2000), Morris; or, on the other hand, whether this promotes more positive images, thus contributing to the process of including people with disabilities; and finally it involves discovering the existence of stigmatising or destigmatising processes because of the media representation of the characters put forward by the resulting productions (Pappous et al., 2009).

Taking the aforementioned research as a reference, a piece of research was designed with the aim of seeking to provide empirical evidence on any possible visual differentiation in the narrations used on television in the different sports modalities considered. First of all, an analysis was made of the visual angle used, appraising how this could condition the portrayal of dependent sportspersons that was being given. Secondly, by means of correlating the statistical data between both modalities, it attempted to ascertain whether the scalar quality and the times of the shots taken coincide, and as a result of this, to analyse the possible partial or total exclusion from the composition of physical limitations, mutilations or the use of artificial limbs.

\section{Methodology}

\section{Sample, Analysis Units and Code Book}

The sports in which most races or events were held at the Peking Olympics 2008, and thus which generated the greatest television audience, were athletics, cycling and swimming, in both the Olympic and Paralympic modalities. According to COI sources, athletics, with 47 events (24 for men and 23 for women) tops the ranking, followed by swimming, with 34 events (17 for men and 17 for women), and finally cycling with 18 events (11 for men and 7 for women). In other Olympic sports the number of events is much lower, canoeing with 16, weightlifting with 15 and rowing with 14 events.

As regards the Paralympic events, according to the Organising Committee of the Peking Paralympics in 2008 and the International Paralympics Committee (CPI), it is the same sports which provide the greatest number of 
television hours. The top event was athletics, with 99, cycling with 44 events and finally swimming, with 27 events. Other adapted sports have less media presence, such as weightlifting, with 20 events, fencing with 10 and archery with 9 .

Taking into account the greater presence on television of the aforementioned three sports events as opposed to other minority ones, the data of 12 sports competitions was taken, with a total number of 152 shot-sequences or analysis units and a Time Code of $1425 \mathrm{sec}$. (23.75 min). The competitions considered for this study were as follows:

1) Athletics

Athletics event, 1 Paralympic (PA1p). Final of the 100 metres race category T44 of men's athletics.

Athletics event, 2 Paralympic (PA2p). Final of the 100 metres race in women's category T44.

Athletics event, 3 Olympic (PA3o). Final of the 100 metres race in men's category. Gold to Usain Bolt (JAM).

Athletics event, 4 Paralympic (PA4o). Final of the 100 metres race for women.

2) Cycling

Cycling event, 1 Paralympic (PC1p). Final of men's track cycling. Individual speed.

Cycling event, 2 Paralympic (PC2p). Final of women's track cycling. Individual speed.

Cycling event, 3 Olympic (PC3o). Final of men's track cycling. Individual speed Sprint.

Cycling event, 4 Olympic (PC40). ). Final of women's track cycling. Individual speed. Sprint.

3) Swimming

Swimming event, 1 Paralympic (PN1p). Final of the women's 50 metres freestyle swimming S5 category.

Swimming event, 2 Paralympic (PN2p). Final of the men's 200 metres S4 freestyle.

Swimming event, 3 Olympic (PN3o). Final of the women's 50 metres freestyle.

Swimming event, 4 Olympic (PN4o). Final of the men's 200 metres freestyle.

Since it was impossible to find any typological coincidences of the Olympic cycling events with the corresponding Paralympic ones, two individual speed events have been correlated, with different track distances. Information about the television production in the same partial and time space of the event was obtained for this purpose.

Scalarity quality of the shot were, a) close-up; b) medium shot; c) "knee" or three-quarter shot; d) long shot; e) full shot; f) extreme long shot.

Position of the camera in respect of the subject, a) normal angle; b) high angle; c) low angle.

Duration of the shot, in seconds (sec).

Modality. Dichotomous variables, turned into dummy variables to be able to work out the calculation of Pearson's correlation coefficient; (1) = Olympiad; (2) = Paralympics.

After coding the units in the sample, the coding process needs to involve the work of external raters so as to be able to guarantee the objectivity of the source coding of the research. This is a guarantee to rule out any contamination of the scientific data, as this process ensures that this data is obtained regardless of the event, instrument or person measuring it (Krippendorff, 1990: p. 232; Weber, 1994). This analysis will assess whether the same content is appraised similarly by an external coder who has not taken part in the initial coding of the research.

For the experimental performance of this type of process, the recommendation is to take a sample never under 50 nor over 300 units (Igartua, 2006: p. 219) and this was completed by two students from 4th year Audiovisual Communication Grade. As a sample of 152 units was obtained in the 12 events considered, one of the external analysts coded 4 Olympic events PA3o, PA4o, PN3o and PN4o with a total number of $(n=56)$ analysis units. The other analyst coded Paralympic events PN2p, PC1p, PN1p, PC2p $(n=52)$. To obtain the intercoder reliability Scott's Pi $(\pi)$ index was used (between -1 and +1 ), giving a mean value of 0.78 . The agreement rate found proved to be $84 \%$.

Scott's $\mathrm{Pi}(\pi)$ (between -1 and +1 ) was used to obtain the intercoder reliability, giving a mean value of 0.78 . The agreement rate observed was $84 \%$.

\section{Results}

None of the units analysed involved any use of the low-angle shot, except the underwater nadir plane (a $180^{\circ}$ low angle shot) in the swimming events, which was not considered through being specific to these tests and not transposable to others. A chi-square test showed statistical significance, though very slight, between the 12 events analysed and the camera angle (see Table 1). 
Table 1. Crosstabs: competitions considered and position of the camera in respect of the subject (angle).

\begin{tabular}{|c|c|c|}
\hline & High angle & Low angle \\
\hline \multicolumn{3}{|c|}{ Paralympics } \\
\hline PA1p & $n=7(41.2 \%)$ & $n=10(58.8 \%)$ \\
\hline PA2p & $n=4(57.1 \%)$ & $n=3(42.9 \%)$ \\
\hline PC1p & $n=3(50.0 \%)$ & $n=3(50.0 \%)$ \\
\hline PC2p & $n=2(25.0 \%)$ & $n=6(75.0 \%)$ \\
\hline PN1p & $n=10(62.5 \%)$ & $n=6(37.5 \%)$ \\
\hline PN2p & $n=8(36.4 \%)$ & $n=14(63.6 \%)$ \\
\hline Total & $n=34$ & $n=42$ \\
\hline \multicolumn{3}{|c|}{ Olympics } \\
\hline РАЗо & $n=7(70.0 \%)$ & $n=3(30.0 \%)$ \\
\hline PA4o & $n=6(66.7 \%)$ & $n=3(33.3 \%)$ \\
\hline РC3o & $n=2(22.2 \%)$ & $n=7(77.8 \%)$ \\
\hline PC4o & $n=3(27.3 \%)$ & $n=8(72.7 \%)$ \\
\hline PN3o & $n=10(58.8 \%)$ & $n=7(41.2 \%)$ \\
\hline PN4o & $n=16(80.0 \%)$ & $n=4(20.0 \%)$ \\
\hline Total & $n=44$ & $n=32$ \\
\hline
\end{tabular}

$\left[\mathrm{X}^{2}(11, \mathrm{~N}=152)=20,598, p<0.038, \eta 0.085\right]$.

The correlation between the event and the scalarity of the shots used indicates that the shot size most widely used is the medium-distance shot (26.31\%) and the ones least used are the "knee" or three-quarter shot, the long shot and close-up (11.84\%), respectively. It has also been observed that the size of the shots used in television production for the different events is considerably similar depending on the sports event in question, that is, the null hypothesis can be rejected, asserting that there is no significant association between both variables $p<$ 0.994. This means that the visual composition in the portrayal of sportspersons with disability is very similar to that of participants in the Olympic games (see Table 2).

The duration of the shots is highly dependent on the sports event taking place, $\left[X^{2}(308, N=152)=363,069\right.$, $p<0.017$, the type of production thus being classified with the different sports events, irrespective of the Olympics or Paralympics.

As regards the possible representation differences between the Olympic and Paralympic modalities, after analysing the camera angle used in the sports broadcasts under consideration, the statistics indicate that the visual angle defining the television narration of these events is identical, though with a slightly positive correlation according to whether these are Olympic or Paralympic games.

Depending on result $\left[X^{2}(1, N=152)=2633, p<0.072\right]$ the angles of the shots coincide to a great extent in both modalities. The hypothesis of a differentiation in production stemming from the compositional angle of the multi-camera device can thus be rejected.

As regards the scalar quality of the shots used, a differentiation in the two modalities cannot be established either.

The result $\left[X^{2}(5, N=152)=3237, p<0.663\right]$ indicates that there is no statistic dependency between the "modality" variable and "scalarity". The slight differences in the size of the shots observed are due to the internal editing of the audiovisual text and to the progress of a sports event broadcast live and not to any intentionality in the composition to display or conceal any prostheses and amputations of the athletes in adapted sports.

It should also be pointed out that in both modalities the high-angle shot or shot from above is the one most widely used in the main openings of the shot-sequence. In the case of closer shots the angle taken is normalised towards the medium shot. 
Table 2. Crosstabs: competitions considered and scalarity quality of the shot

\begin{tabular}{|c|c|c|c|c|c|c|}
\hline & Close-up & Medium shot & $3 / 4$ shot & Long shot & Full shot & + Long shot \\
\hline \multicolumn{7}{|c|}{ Paralympics } \\
\hline PA1p & $n=2(11.8 \%)$ & $n=2(11.8 \%)$ & $n=2(11.8 \%)$ & $n=3(17.6 \%)$ & $n=6(35.3 \%)$ & $n=2(11.8 \%)$ \\
\hline PA2p & $n=1(14.3 \%)$ & $n=2(28.6 \%)$ & $n=1(14.3 \%)$ & $n=1(14.3 \%)$ & $n=1(14.3 \%)$ & $n=1(14.3 \%)$ \\
\hline PC1p & $n=1(16.7 \%)$ & $n=1(16.7 \%)$ & $n=1(16.7 \%)$ & $n=1(16.7 \%)$ & $n=1(16.7 \%)$ & $n=1(16.7 \%)$ \\
\hline PC2p & $n=1(12.5 \%)$ & $n=3(37.5 \%)$ & $n=1(12.5 \%)$ & $n=1(12.5 \%)$ & $n=1(12.5 \%)$ & $n=1(12.5 \%)$ \\
\hline PN1p & $n=1(6.3 \%)$ & $n=6(37.5 \%)$ & $n=1(6.3 \%)$ & $n=2(12.5 \%)$ & $n=5(31.3 \%)$ & $n=1(6.3 \%)$ \\
\hline PN2p & $n=5(22.7 \%)$ & $n=5(22.7 \%)$ & $n=1(4.5 \%)$ & $n=2(9.1 \%)$ & $n=1(4.5 \%)$ & $n=8(36.4 \%)$ \\
\hline Total & $n=11$ & $n=19$ & $n=7$ & $n=10$ & $n=15$ & $n=14$ \\
\hline \multicolumn{7}{|c|}{ Olympics } \\
\hline РАЗО & $n=1(10.0 \%)$ & $n=4(40.0 \%)$ & $n=1(10.0 \%)$ & $n=1(10.0 \%)$ & $n=3(30.0 \%)$ & $n=0(00.0 \%)$ \\
\hline PA4o & $n=1(11.1 \%)$ & $n=3(33.3 \%)$ & $n=1(11.1 \%)$ & $n=1(11.1 \%)$ & $n=1(11.1 \%)$ & $n=2(22.2 \%)$ \\
\hline РСЗо & $n=1(11.1 \%)$ & $n=1(11.1 \%)$ & $n=1(11.1 \%)$ & $n=1(11.1 \%)$ & $n=3(33.3 \%)$ & $n=2(22.2 \%)$ \\
\hline PC4o & $n=1(9.1 \%)$ & $n=2(18.2 \%)$ & $n=2(18.2 \%)$ & $n=1(9.1 \%)$ & $n=3(27.3 \%)$ & $n=2(18.2 \%)$ \\
\hline PN3o & $n=2(11.8 \%)$ & $n=4(23.5 \%)$ & $n=2(11.8 \%)$ & $n=2(11.8 \%)$ & $n=6(35.3 \%)$ & $n=1(5.9 \%)$ \\
\hline PN4o & $n=1(5.0 \%)$ & $n=7(35.0 \%)$ & $n=4(20.0 \%)$ & $n=2(10.0 \%)$ & $n=3(15.0 \%)$ & $n=3(15.0 \%)$ \\
\hline Total & $n=7$ & $n=21$ & $n=11$ & $n=8$ & $n=19$ & $n=10$ \\
\hline
\end{tabular}

$[\mathrm{X} 2(55, \mathrm{~N}=152)=32,086, p<0.994, \eta 0.110]$.

In the same way, the length of the shots into which each of the sports events broadcast on television is divided does not depend on the modality, $\left[\mathrm{X}^{2}(28, \mathrm{~N}=152)=35,029, p<0.169\right]$, as the time-splitting of the discourse coincides, with small chronological variations due to the natural development of the events being observed. For this reason it is not possible to assure there is any intention to keep the athletes covered by the research in the shot for more or less time.

Lastly, the resolution of Student's t test for independent samples considering the angle variable as a group variable indicated that the contrast significance value is not significant in any of these; [ $(150)=1039, p<0.300]$ for the modality, and [ $\mathrm{t}(150)=1626, p<0.106]$ in the event variable. With the scalar quality as grouping variable, no form of association was obtained either: [ $\mathrm{t}(56)=0.951, p<0.346]$ for the modality and $[\mathrm{t}(56)=0.462$, $p<0.646$ ] for event.

\section{Discussion}

Just as Pappous (2006, 2009) limited his research objecttives in the location of seven constructs categorising the theoretical framework of stigmatisation or liminality in the context of media portrayal of Paralympic athletes by photographs in the European press, this research work was able to come to conclusions as to the dimensions of stigmatisation and destigmatisation in television broadcasting during the Paralympic Games in Peking 2008.

The subtle explicit and implicit expressions of a certain stigmatisation by representing passiveness, fragility, dependence or infantilisation discovered in previous research (Pappous et al., 2007; Marcellini \& Pappous, 2006; Leseleuc, Marcelliniand, \& Pappous, 2006) were not found in this study.

First of all Léséleuc's et al. (2009) conclusions can be supported, observing that when one works with proportions based on variables structuring the internal logic of the sports media coverage (number of participants and medals obtained) the figures obtained show that there is no discrimination in respect of the media coverage of sportspersons with disabilities. In the logic of sports media coverage, no quantitative under-representation can be perceived.

The selection of the spatial reference framework in the television production of the twelve sports events stu- 
died was very much in agreement. The linking of the shots and the choice of the camera angle in Paralympic events has not revealed any indication of intentionality in the creation of a specific model for portrayal of disability in elite sports. The possibility of the existence of implicit cognitive implications in terms of representation of stigmatisation is not in any case due to the visual reading that can be drawn from this television event.

Although it lies outside the bounds of this research, it would be important to examine the pre-production processes of the filming and production teams of these broadcasts, ultimately to learn the intentionality of the professionals in the final results and the possible existence of a journalism specialising in disability, called as productive routines.

The methodology and the data obtained in this study are totally different from those of any other research within the same area of knowledge. In contrast with investigations based on the empirical observation of people with disabilities photographically captured from different angles; on the persuasive power of advertising material photographed under different compositions; or even on mascots in sporting events of people with disabilities (Butler \& Bissell, 2013), the novelty of this study lies in the analysis of the moving image.

Most of the studies cited reveal an explicit stigmatization of sportsmen with disabilities, after being analyzed under the discursive paradigm or from the still photographic iconography. So far scientific literature has not tackled the narrative TV treatment of sportspersons with a disability during a Paralympic Games.

The conclusive evidence thrown by this investigation makes it possible to state that the sportspersons are shown by the TV with a narrative similar to that of abled ones during the Paralympic games and consequently it is not possible to endorse a deliberate stigmatization view.

After this investigation the need arises to analyze future editions of the Paralympic Games in order to confirm the tendency shown here and the advancements in social equity which emerges from them. In addition, it is deemed necessary to correlate and assess the effects and levels of visual stigmatization after the exposure of this constructs to potential observers.

\section{References}

Arnheim, R. (1974). Art and Visual Perception. Berkeley, CA: University of California Press.

Barnes, C. (1992). Disabling Imagery and the Media: An Exploration of the Principles for Media Representations of Disabled People. Ryburn: Krumlin.

Beckett, A. (2006). Citizenship and Vulnerability: Disability and Issues of Social and Political Engagement. New York: Palgrave Macmillan. http://dx.doi.org/10.1057/9780230501294

Blanco, J. M. (2001). Las retransmisiones deportivas como género periodístico espectacular y dramático. ZER: Revista de Estudios de Comunicación, 11, 227-272.

Bogdan, R., \& Taylor, S. (1989). Relationships with Severely Disabled People: The Social Construction of Humanness. Social Problems, 36, 135-148. http://dx.doi.org/10.2307/800804

Butler, S., \& Bissell, K. (2013). “The Best I Can Be”: Framing Disability Through the Mascots of the 2012 Summer Olympics and Paralympics. Communication and Sport, 1-19. http://dx.doi.org/10.1177/2167479513500137

Cooke, C., Daone, L., \& Morris, G. (2000). Stop Press! How the Press Portrays People with Disabilities. London: Scope.

Depauw, K. (2000). Social Cultural Context of Disability: Implications for Scientific Inquiry and Professional Preparation. Quest, 52, 358-368. http://dx.doi.org/10.1080/00336297.2000.10491723

Ellis, K. (2009). Beyond the Aww Factor: Human Interest Profiles of Paralympians and the Media Navigation of Physical Difference and Social Stigma. Asia Pacific Media Educator, 19, 23-36.

Goffman, E. (1963). Estigma. La identidad deteriorada. Buenos Aires: Amorrortu.

Goggin, G. (2008). Innovation and Disability. M/C Journal of Media and Culture, 11.

Green, K., \& Tanner, S. (2000). Reporting Disability. Asia Pacific Media Educator, 19, 43-54.

Haller, B. (1995). Camera Angle and Media Representations of People with Disabilities. Washington, DC: Media and Disability Interest Group, Association for Education in Journalism and Mass Communication Annual Meeting.

Hardin, M. (2002). Reflections of Passivity and Resistance: Wheelchair Athletes Discuss Sport Media. Paper Presented at the National Communication Association Annual Meeting, New Orleans, 1-18.

Hartmann-Tews, I., \& Rulofs, B. (2003). GenderRepresentation in Sports Media. Paper Presented at the 2nd World Conference of Sport Sociology, Cologne: German Sport School.

Howe, D. (2008). From Inside the Newsroom: Paralympic Media and the “Production” of Elite Disability. International Re- 
view for the Sociology of Sport, 43, 135-150. http://dx.doi.org/10.1177/1012690208095376

Igartua, J. J. (2006). Métodos cuantitativos de investigación en comunicación. Barcelona: Bosch.

Kell, P., Kell, M., \& Price, N. (2008). Two Games and one movement? The Paralympics and the Olympic Movement. In P. Kell, W. Vialle, D. Konza, \& G. Vogl (Eds.), Learning and the Learner: Exploring Learning for New Times (pp. 65-77), Wollongong: University of Wollongong.

Knoll, J.A. (1987). Through a Glass, Darkly: Thephotographicimage of Peoplewith a Disability. Doctoral Tesis, Syracuse: Universidad de Syracuse.

Kraft, R. N. (1987). The Influence of Camera Angle on Comprehension and Retention of Pictorial Events. Memory and Cognition, 15, 291-307. http://dx.doi.org/10.3758/BF03197032

Krippendorff, K. (1990). Metodología de análisis de contenido. Teoría y práctica. Barcelona: Paidós.

Léséleuc, E., Pappous, A., \& Marcellini, A. (2009). La cobertura mediática de las mujeres deportistas con discapacidad. Análisis de la prensa diaria de cuatro países europeos durante los Juegos Paralímpicos de Sidney 2000. Apunts, Educació Física i Esports, 3, 80-88. http://dialnet.unirioja.es/servlet/articulo?codigo=3079153

Longmore, P. (1987). Screening Stereotypes: Images of Disabled People in Television and Motion Pictures. In A. Gartner, \& T. Joe (Eds.), Images of the Disabled, Disabling Images (pp. 65-78). New York: Praeger.

Maathuis, I. (2010). How Camera Angles Influence People's Opinions about Object. Enschede: University of Twente, Faculty of Behavioral Sciences, Department of Psychology, 1-22.

Mandell, L. M., \& Shaw, D. L. (1973). Judging People in the News. Unconsciously: Effect of Camera Angle and Bodily Activity. Journal of Broadcasting, 17, 353-362. http://dx.doi.org/10.1080/08838157309363698

Marcellini, A., Léséleuc, É., \& Gleyse, J. (2003). L’intégration sociale par le sport des personnes handicapées. Revue Internationale de Psychosociologie, 20, 59-72. http://dx.doi.org/10.3917/rips.020.0059

Mitchell, D., \& Snyder, S. (2000). Narrative Prothesis: Disability and the Dependencies of Discourse. Ann Arbor, MI: University of Michigan Press.

Mitry, J. (1978). Estética y Psicología del cine. Volumen I y II. Madrid: Siglo XXI.

Monaco, J. (1977). How to Read a Film. New York: Oxford University Press.

Norden, M. (1994). The Cinema of Isolation: A History of Physical Disability in the Movies. New Brunswick, NJ: Rutgers University Press.

Oliver, M., \& Barnes, C. (1998). Social Policy and Disabled People: From Exclusion to Inclusion. London: Longman.

Pappous, A., Marcellini, A., De Leseleuc, E., Río-Valle, S., Quintana, F. C., García Caro, M. P., \& Muñóz-Vinuesa, A. (2009). La representación mediática del deporte adaptado a la discapacidad en los medios de comunicación. Ágora para la Educación Física y el Deporte, 1, 31-42.

Schantz, O. J., \& Gilbert, K. (2001). An Ideal Misconstrued: Newspager Coverage of the Atlanta Paralympic Games in France and Germany. Sociology of Sport Journal, 18, 69-94.

Schell, L. A., \& Duncan, M. (1999). A Content Analysis of CBS’s Coverage of the 1996 Paralympic Games. Adapted Physical Activity Quarterly, 16, 27-47.

Scotch, R. K. (1988). Disability as the Basis for a Social Movement: Advocacy and Politics of Definition. Journal of Social Issues, 44, 159-172. http://dx.doi.org/10.1111/j.1540-4560.1988.tb02055.x

Smith, A., \& Thomas, N. (2005). The "Inclusion” of Elite Athletes with Disabilities in the 2002 Manchester Commonwealth Games: An Exploratory Analysis of British Newspaper Coverage. Sport, Education and Society, 10, 49-67.

http://dx.doi.org/10.1080/1357332052000298809

Sontag, S. (1977). On Photography. New York: Dell.

Susman, J. (1994). Disability, Stigma and Deviance. Social Science and Medicine, 38, 15-22. http://dx.doi.org/10.1016/0277-9536(94)90295-X

Sutherland, A. (1997). Black Hats and Twisted Bodies. In A. Pointon, \& C. Davies (Eds.), Framed: Interrogating Disability in the Media, BFI, London, 16-20.

Taylor, J. (1974). Design and Expression in the Visual Arts. New York: Dover.

Tiemans, R. K. (1970). Some Relationships of Camera Angle to Communicator Credibility. Journal of Broadcasting, 14, 483-490.

Thomas, N., \& Smith, A. (2003). Preoccupied with Able Bodiedness? An Analysis of the British Media Coverage of the 2000 Paralympics Games. Adapted Physical Activity Quarterly, 20, 166-181.

Weber, R. P. (1994). Basic Content Analysis. In Lewis-Beck, Michael S. (comp.): Research Practice (pp. 251-338). Thousand Oaks, CA: Sage. 